\title{
Viral Metagenomic-Based Screening of Sugarcane from Florida Reveals Occurrence of Six Sugarcane-Infecting Viruses and High Prevalence of Sugarcane yellow leaf virus
}

D. Filloux and E. Fernandez, CIRAD, BGPI, Montpellier, France, and BGPI, INRA, CIRAD, SupAgro, Univ Montpellier, Montpellier, France; J. C. Comstock, Sugarcane Field Station, United States Department of Agriculture-Agricultural Research Service (USDA-ARS), Canal Point, FL 33438; D. Mollov, USDA-ARS, National Germplasm Resources Laboratory, Beltsville, MD 20705; P. Roumagnac, CIRAD, BGPI, and BGPI, INRA, CIRAD, SupAgro; and P. Rott, ${ }^{\dagger}$ University of Florida, Department of Plant Pathology, Everglades Research \& Education Center, Belle Glade 33430

\begin{abstract}
A viral metagenomics study of the sugarcane virome in Florida was carried out in 2013 to 2014 to analyze occurrence of known and potentially new viruses. In total, 214 sugarcane leaf samples were collected from different commercial sugarcane (Saccharum interspecific hybrids) fields in Florida and from other Saccharum and related species taken from two local germplasm collections. Virion-associated nucleic acids (VANA) metagenomics was used for detection and identification of viruses present within the collected leaf samples. VANA sequence reads were obtained for 204 leaf samples and all four previously reported sugarcane viruses occurring in Florida were detected: Sugarcane yellow leaf virus (SCYLV,

150 infected samples out of 204), Sugarcane mosaic virus (1 of 204), Sugarcane mild mosaic virus (13 of 204), and Sugarcane bacilliform virus (54 of 204). High prevalence of SCYLV in Florida commercial fields and germplasm collections was confirmed by reverse-transcription polymerase chain reaction. Sequence analyses revealed the presence of SCYLV isolates belonging to two different phylogenetic clades (I and II), including a new genotype of this virus. This viral metagenomics approach also resulted in the detection of a new sugarcane-infecting mastrevirus (recently described and named Sugarcane striate virus), and two potential new viruses in the genera Chrysovirus and Umbravirus.
\end{abstract}

Sugarcane (Saccharum interspecific hybrids) is a major agricultural crop throughout the tropics and subtropics due to its high sucrose content and potential for bioenergy production. This plant is the highest-value row crop in Florida, and planting disease-resistant varieties is a major goal of sugarcane growers. Resistant varieties (Canal Point [CP] series) are produced in Florida by a tripartite cooperative breeding program among the United States Department of Agriculture (USDA), the University of Florida, and the Florida Sugar Cane League.

Sugarcane is host to more than 100 pathogens, and most of the resulting diseases are major limiting factors of sugarcane production (Rott et al. 2000). Viruses are especially problematic from both a production and breeding perspective. The symptoms they cause are often inconspicuous and can escape visual detection. Only a few sugarcane viruses can be mechanically transmitted and their natural transmission via insects is generally erratic. This creates challenges in screening for resistance in breeding programs. Furthermore, because sugarcane is propagated vegetatively via stalk cuttings, virus-infected material can rapidly be propagated in nurseries and commercial fields.

Four virus diseases have been reported in commercial sugarcane fields or in germplasm collections in Florida: (i) leaf fleck caused by Sugarcane bacilliform virus (SCBV), a badnavirus of the Caulimoviridae

${ }^{\dagger}$ Corresponding author: P. Rott; E-mail: pcrott@ufl.edu

Funding: This research would not have been possible without funding provided by the Florida Sugar Cane League (project number 00107475 and fund number F000057). This work is supported by the USDA National Institute of Food and Agriculture (project Hatch/Rott FLA-BGL-005404).

*The $\boldsymbol{e}$-Xtra logo stands for "electronic extra" and indicates that one supplementary table and three supplementary figures are published online.

Accepted for publication 23 May 2018.

This article is in the public domain and not copyrightable. It may be freely reprinted with customary crediting of the source. The American Phytopathological Society, 2018. family (Lockhart and Autrey 1988, 2000b); (ii) mild mosaic caused by Sugarcane mild mosaic virus (SCMMV), an unclassified member of the Closteroviridae family (Lockhart and Autrey 2000a; Lockhart et al. 1992); (iii) mosaic caused by Sugarcane mosaic virus (SCMV), a potyvirus of the Potyviridae family (Grisham 2000; Koike and Gillaspie 1989); and (iv) yellow leaf caused by Sugarcane yellow leaf virus (SCYLV), a polerovirus of the Luteoviridae family (Moonan et al. 2000; Rott et al. 2008; Smith et al. 2000).

SCBV is widespread in the U.S. sugarcane germplasm collections (Comstock and Lockhart 1990) but its prevalence and effect on yields in Florida commercial fields is unknown. This virus is transmitted by stalk cuttings and vectored by mealybugs such as the pink sugarcane mealybug (Saccharicoccus sacchari) and the gray sugarcane mealybug (Dysmicoccus boninsis). Most sugarcane varieties infected with SCBV do not exhibit foliar symptoms (Lockhart and Autrey 2000b). SCMMV has been found naturally in sugarcane only in mixed infections with SCBV (Lockhart and Autrey 2000a). The virus has been reported in Australia, Colombia, Costa Rica, Malawi, Mauritius, South Africa, Thailand, and the United States (Florida and Hawaii). Most varieties infected by SCMMV are symptomless and the effect of the virus on sugarcane growth is unclear. Like SCBV, SCMMV is also spread by the pink sugarcane mealybug (Lockhart and Autrey 2000a).

Sugarcane mosaic is one of the most widespread virus diseases of sugarcane and has affected the world industry by causing significant yield reductions at one time or another (Koike and Gillaspie 1989). Symptoms are patterns of contrasting shades of green on the leaf lamina. The disease was initially attributed to a single virus with numerous strains that were transmitted by several aphid species. Mosaic is caused by either single or mixed infections of SCMV and Sorghum mosaic virus (Grisham 2000). Both viruses occur in Louisiana but, thus far, only SCMV has been reported in Florida. Mosaic disease had not been a problem in Florida until 1996, when it was observed on a major sugarcane cultivar in growers' fields (Rott et al. 2015). It was controlled by replacing susceptible cultivar CP72-2086 with newly developed resistant varieties. Sugarcane mosaic disease is currently regarded as a potential threat in Florida.

Yellow leaf (previously known as yellow leaf syndrome) was first recognized in Florida in 1993 but the disease had likely been present 
in the state several years before then (Comstock et al. 1994). SCYLV, the causal agent of yellow leaf, has been found in most sugarcanegrowing locations worldwide, and consists of at least eight genotypes: BRA, CHN1, CHN3, CUB, HAW, IND, PER, and REU (Lin et al. 2014). Leaf symptoms of the disease include yellowing of the lower side of the midrib and necrosis starting from the leaf tip. SCYLV is widespread in Florida germplasm collections but only a few infected varieties exhibit leaf symptoms (Rott et al. 2016). SCYLV is vectored by several aphid species, among which Melanaphis sacchari appears to be the most common and efficient in the Western hemisphere. SCYLV caused stalk weight reductions of $11 \%$ in experimental plots in Florida (Comstock and Miller 2004), and yield losses of up to $25 \%$ have been reported in Brazil (Rott et al. 2008).

Both known and unknown (i.e., new, uncharacterized, or undetected) viruses threaten the sugarcane industry. Monitoring germplasm collections for virus infections is particularly important because they are widely distributed and used as sources for breeding material. Environmental shotgun and metabarcoding sequencing has proven to be effective to better inventory nonculturable pathogens such as viruses. Viral metagenomics has revolutionized the way pathologists decipher viral diseases, and has already produced key advances in viral ecology (Roossinck 2012; Roossinck et al. 2015). Viral metagenomics is also a powerful approach for virus surveillance (Candresse et al. 2014) and screening at regional or ecosystem scales (Bernardo et al. 2018; Muthukumar et al. 2007, 2009; Palanga et al. 2016; Roossinck et al. 2010). The objective of this study was to determine the prevalence of known and potentially new viruses in commercial sugarcane fields and germplasm collections in Florida using a metagenomics approach.

\section{Materials and Methods}

Plant material and sample preparation. In total, 214 leaf samples from different species of Saccharum and related genera were collected in 2013 to 2014 from commercial fields in the Everglades Agricultural Area (Belle Glade, Clewiston, and Okeelanta, FL) $(n=$ 68), the historical variety collection of U.S. Sugar in Clewiston $(n=$ 32 ), and the germplasm collection of USDA Agricultural Research Service (ARS) in Canal Point, FL $(n=114)$. The germplasm collection in Canal Point was a core collection from the world collection of sugarcane and related grasses of USDA-ARS in Miami, FL (Todd et al. 2014). Freshly collected leaf pieces taken from the top visible dewlap leaf were dried on $\mathrm{CaCl}_{2}$ and then shipped to CIRAD in Montpellier, France, where all samples were further processed.

Virion-associated nucleic acids extraction, cDNA amplification, sequencing, and sequence analysis. A virion-associated nucleic acids (VANA)-based metagenomics approach was used to identify virus sequences in each of the 214 plant samples, as described by Palanga et al. (2016). Briefly, $750 \mathrm{mg}$ of leaf tissue from each plant sample was homogenized in Hanks' buffered salt solution (1:10) with four ceramic beads (MP Biomedicals) and centrifuged at $3,200 \times g$ for $5 \mathrm{~min}$. Each supernatant $(6 \mathrm{ml})$ was then centrifuged at $8,228 \times g$ for $3 \mathrm{~min}$, filtered through a $0.45-\mu \mathrm{m}$ sterile syringe filter, and centrifuged at $148,000 \times g$ for $2.5 \mathrm{~h}$ at $4^{\circ} \mathrm{C}$ to concentrate viral particles. Nonencapsidated nucleic acids were eliminated by adding $15 \mathrm{U}$ of bovine pancreatic DNase I (Euromedex) and $1.9 \mathrm{U}$ of bovine pancreatic RNase A (Euromedex) followed by an incubation at $37^{\circ} \mathrm{C}$ for $90 \mathrm{~min}$. Total nucleic acids were finally extracted from $100 \mu \mathrm{l}$ of resuspended virions using the NucleoSpin 96 Virus Core Kit (Macherey-Nagel) following the manufacturer's protocol. Total nucleic acids were used to produce single-strand cDNA libraries by incubation of $10 \mu \mathrm{l}$ of extracted viral nucleic acids with $100 \mathrm{pmol}$ of primer DoDec (5'-CCTTCGGATCCTCCNNNNNNNNNNNN$\left.3^{\prime}\right)$ at $85^{\circ} \mathrm{C}$ for $2 \mathrm{~min}$. Double-stranded cDNA libraries were produced by Klenow polymerization with $2 \mu \mathrm{M}$ primer DoDec. Tagged DNA amplicons from 96 samples using the set of 96 primers described by Palanga et al. (2016) were pooled to split the 214 sugarcane samples from Florida into three libraries composed of 96 samples each (samples 1 to 96 in library 1, samples 97 to 192 in library 2, and samples 193 to $214+74$ samples from another project in library 3), and sequenced using the Roche 454 sequencing system (Beckman Coulters Genomics). De novo contig assembly of cleaned reads was performed for each sample using CAP3 (Huang and Madan 1999). Taxonomic assignment of contig sequences and nonassembled reads was determined using BLASTn and BLASTx (Altschul et al. 1990), and the nt and nr GenBank databases.

Detection of SCYLV by reverse-transcription polymerase chain reaction. Detection of SCYLV in plant samples containing VANA reads was performed by reverse-transcription polymerase chain reaction (RT-PCR) with primers scylvf1 and scylvr1, as described by Girard et al. (2010).

Recovery of the entire coding sequence (ORF0 to ORF5) of the genomes of SCYLV and phylogenetic analyses. Three plant samples that yielded 913 to 3,624 VANA SCYLV-matching reads were used to assemble the entire coding sequence (ORF0 to ORF5) of the virus by pairing end sequences using Geneious R11 (Biomatters Limited). Entire consensus coding genome sequences (consensus threshold set to 50\%) of these three isolates (FL84, FL86, and FL180) were aligned using MUSCLE to 36 entire genome sequences of SCYLV retrieved from GenBank (Edgar 2004). A phylogenetic tree was inferred using PhyML3.0 (Guindon et al. 2010), with substitution model GTR+G+I selected as best-fit model by jModelTest (Darriba et al. 2012) and 500 bootstraps (Fig. 1). Additionally, consensus genome sequences (consensus thresholds ranging from 50 to 99\%) of SCYLV isolates FL84, FL86, and FL180 were also aligned using MUSCLE to the 36 full genomes sequences retrieved from GenBank. A phylogenetic tree was inferred using PhyML3.0 (Guindon et al. 2010), with substitution model GTR+G+I selected as bestfit model by jModelTest (Darriba et al. 2012) and 500 bootstraps (Supplementary Fig. S1). Pairwise identity matrixes of all fullgenome nucleotide sequences were obtained using the MUSCLEbased pairwise alignment option implemented in SDT v1.2 (Muhire et al. 2014).

Characterization of SCYLV diversity in infected plant samples. The currently available full coat protein $(c p)$ gene sequences of SCYLV $(n=116)$ were downloaded from GenBank and aligned using MUSCLE (Edgar 2004). A phylogenetic tree was inferred using PhyML3.0 (Guindon et al. 2010), with substitution model $\mathrm{K} 2+\mathrm{G}$ selected as best-fit model by jModelTest (Darriba et al. 2012) and 500 bootstraps. The 116 sequences were clearly (bootstrap value $=99 \%$ ) split into two groups (Supplementary Fig. S2): clade I formed by SCYLV genotypes BRA, CHN3, HAW, PER, and REU and clade II comprising genotypes CHN1, CUB, and IND. A visual analysis of the aligned sequences revealed that sequence distribution into these two clades was based on 12 singlenucleotide polymorphisms (SNP). The SNP were located at the following positions of the coat protein: 58 (A for clade I/C for clade II), 88 (G/C), 172 (C/A), 193 (G/A), 207 (A/G), 446 (T/C), 489 (G/A), 508 (T/C), $511(\mathrm{C} / \mathrm{T}), 532(\mathrm{~T} / \mathrm{G}), 533$ (C/G), and 534 (G/A). Therefore, we considered these 12 canonical SNP as markers of clades I and II. The VANA reads obtained from each Florida plant sample were then mapped on the $c p$ nucleotide sequence of BRA isolate CP65-357 (accession number AF157029) using Geneious R11 (Biomatters Limited). Samples for which the depth of coverage was $<10 \times$ for at least 1 of the 12 canonical SNP were discarded from the analysis. The consensus $c p$ sequence of each plant sample was used to determine the frequency of mismatches at each SNP position. Assignment of each virus isolate to one of the two phylogenetic clades was performed using a $1 \%$ threshold. When the frequency of one of the two expected nucleotides was $<1 \%$, the plant sample was considered infected by a single virus isolate belonging to a major clade. When the frequencies of the two expected nucleotides was $>1 \%$, the plant sample was considered coinfected by two isolates, one of each phylogenetic clade.

GenBank accession numbers. The entire coding sequence (ORF0 to ORF5) of the genome sequences of SCYLV isolates FL84, FL86, and FL180 are publicly available in GenBank (accession numbers MH058007 to MH058009). Cleaned reads have been deposited in the sequence read archive of GenBank (accession numbers SAMN08767132 to SAMN08767134). 


\section{Results}

Presence of viral sequences in plant samples. The VANA approach used in this study with 214 leaf samples yielded 304,311 raw reads. After the quality-control process, 5,042 reads (1.56\%) were discarded. No reads were obtained for 10 samples which were removed from the study. The average read count for the remaining 204 sequence-producing plant samples was 1,467 cleaned reads (Supplementary Table S1). Plant virus related sequences were found in 160 of the 204 plant samples $(78.4 \%)$ by BLASTn and BLASTx comparisons between the VANA reads and GenBank sequences. In total, 150 of the 204 plant samples $(73.5 \%)$ contained sequences of SCYLV (Table 1). SCBV, SCMMV, and SCMV sequences were found in $26.5,6.4$, and $0.5 \%$ of the samples, respectively. Four samples were infected by Sugarcane striate virus (SCStV), a newly described mastrevirus (Boukari et al. 2017). In all, 3 samples contained sequences related to umbraviruses and 10 samples contained sequences related to chrysoviruses.

Frequency of viral sequences in different plant species. Among 62 samples from commercial sugarcane fields, 47 (76\%) were infected with SCYLV. A similar incidence of SCYLV was found in the two germplasm collections, with 103 samples (72.5\%) containing SCYLV sequences (Table 1). Within the germplasm collections, SCYLV sequences were found in Saccharum hybrids as well as in Saccharum officinarum, $S$. robustum, $S$. sinense, and $S$. spontaneum. None of the commercial field samples contained sequences of SCMV, SCMMV, or SCStV, and sequences of SCBV were found in only two (3\%) of these samples. SCMV and SCStV were detected in only one and four samples, respectively, of the germplasm collection at Canal Point. The single sample infected by SCMV was from a variety (CP72-2086) that was already known to be infected and that is used to screen for mosaic resistance in the Florida breeding program. The four samples infected by SCStV came from three botanical species (S. barberi, S. officinarum, and S. spontaneum). SCMMV sequences were found in 13 (9\%) of the 142 germplasm collection samples, and 10 of these positive samples were from S. officinarum (Table 1). The other three came from Erianthus spunknow, S. barberi, and $S$. edule. The 54 sequences of SCBV were identified in E. spunknow, S. barberi, S. officinarum, S. robustum, S. spontaneum, and Saccharum hybrids. Among the 75 samples of $S$. officinarum, 42 (56\%) contained SCBV sequences whereas only $7(6.4 \%)$ of the 110 samples of Saccharum hybrids were infected by this virus (Table 1).

Validation of presence of SCYLV in plant samples. In total, 121 plant samples that contained SCYLV sequences also tested positive for this virus by RT-PCR, and 43 samples that were found free of SCYLV sequences also tested negative by RT-PCR. SCYLV was not detected by RT-PCR in 29 samples that contained SCYLV VANA sequences, and 11 samples without SCYLV VANA sequences tested positive by RT-PCR.

Genetic diversity of SCYLV isolates. The entire coding sequence (ORF0 to ORF5) of the genome of three SCYLV isolates was reconstructed using the VANA reads obtained for their respective samples: 3,624, 1,656, and 913 reads for isolates FL84, FL86, and FL180, respectively. These sugarcane samples were each infected by a single genotype of SCYLV because the topology of the phylogenetic tree was not disrupted while including a large range of consensus genome sequences (consensus thresholds ranging from 50 to $99 \%$ ) for isolates FL84, FL86, and FL180. SCYLV isolate 86 belonged to clade I based on its position in the phylogenetic tree constructed with the full genome sequence of 39 virus isolates (36 genome sequences retrieved from GenBank and 3 obtained in this study) (Fig. 1). Isolates FL84 and FL180 belonged to clade II of the same phylogenetic tree. Isolate FL86 clustered with several isolates belonging to genotype BRA, comprising isolates from Brazil, China, Florida, and India (Fig. 1). Isolate FL180 grouped with isolate chn1 from China, known as genotype CHN1. Isolate FL84 was in a separate lineage and clustered only with isolate Sorg1 of sweet sorghum from Florida (genotype undetermined).

Pairwise distribution analysis of the 39 full genome sequences of SCYLV resulted in sequence demarcation thresholds at 90 to 91,95 , and $97 \%$ (Supplementary Fig. S3). At demarcation threshold 90 to $91 \%$, virus isolates were only separated into clades I and II (Fig. 2). Three genotypes were clearly distinguished with a $95 \%$ demarcation threshold: BRA and REU in clade I and CUB in clade II. SCYLV isolates previously known as genotypes HAW, PER, and CHN3 were attributed to genotype BRA because genotype BRA was the first one to be described among them. Similarly, isolates previously known as genotype CHN1 and IND were attributed to genotype CUB because of antecedence in genotype description. At demarcation threshold $97 \%$, clade I contained only two genotypes (BRA and REU) and clade II was split in several genotypes: CHN1, CUB, and three new genotypes named FLA1 (isolates Sorg 1 and FL84), FLA2 (isolate Sorg 2), and FLA3 (isolate Sorg 3) (Fig. 2).

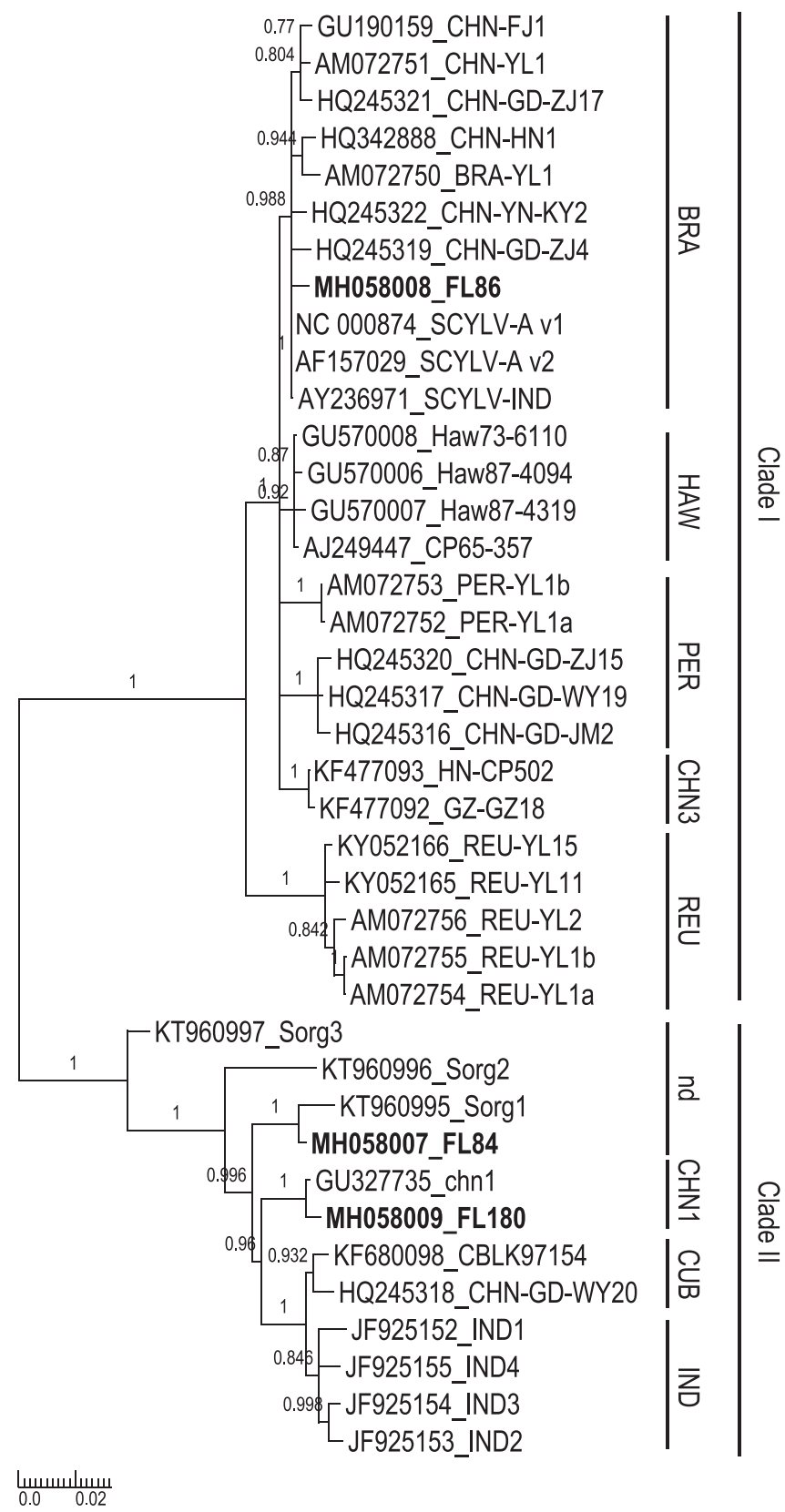

Fig. 1. Phylogenetic tree reconstructed with the near complete (ORF0 to ORF5) genome sequence of 36 isolates of Sugarcane yellow leaf virus (SCYLV) retrieved from GenBank and three isolates of SCYLV obtained herein (FL84, FL86, and FL180, with consensus threshold set to $50 \%$ ). The phylogenetic tree was inferred using PhyML3.0 (Guindon et al. 2010), with substitution model GTR+G+I selected as best-fit model by jModelTest (Darriba et al. 2012). Bootstrap values based on 500 replications are indicated at branches. Scale bar units are in number of substitutions per nucleotide. Bold vertical lines correspond to the two clades and genotypes of SCYLV described in the text (nd = genotype not determined). 
SCYLV-related VANA reads were mapped to the $c p$ gene for 138 plant samples from Florida. These sequences were used to assign SCYLV isolates to phylogenetic clades I or II using the novel SNP-calling approach based on 12 canonical SNP located in the SCYLV $c p$ gene, as described above. There was $>10 \times$ coverage for all 12 canonical SNP among 71 of the 138 samples. Sequences of phylogenetic clade I were found in 37 samples (52\%), and 30 samples $(42 \%)$ contained sequences of phylogenetic clade II (Table 2). Additionally, four samples (6\%) were found with sequences of both clades. Saccharum hybrids contained sequences of SCYLV clade I and clade II in 34 and 9 samples, respectively. S. officinarum contained sequences of clades I and II in 7 and 25 samples, respectively, including 4 samples with sequences of both clades (Table 2).

Identification of new viral sequences. In total, 21 sequences related to the genus Umbravirus were detected in two S. officinarum plants from the germplasm collection in Canal Point and in one plant from a commercial field. The size of the four contigs that were assembled from umbravirus-related VANA reads varied from 211 to 499 nucleotides, with the highest nucleotide identity (58\%) to carrot mottle mimic umbravirus. Additionally, 26 sequences related to the genus Chrysovirus were found in six samples collected in commercial sugarcane fields and in four samples from the germplasm collection in Canal Point (three S. officinarum and one S. barberi). The size of five contigs that were assembled from the chrysovirusrelated VANA reads varied from 180 to 476 nucleotides, with $98 \%$ nucleotide identity to Persea americana chrysovirus.

\section{Discussion}

Metagenomics-based screening allowed us to detect all four sugarcane viruses previously reported in Florida: SCYLV (Luteoviridae), the causal agent of yellow leaf; SCMV (Potyviridae), the causal agent of mosaic; SCMMV (Closteroviridae), the causal agent of mild mosaic; and SCBV (Caulimoviridae), the causal agent of leaf fleck. Two additional new sugarcane-infecting viruses were also detected: SCStV (Geminiviridae), the causal agent of sugarcane striation (Boukari et al. 2017), and an undetermined umbravirus (Tombusviridae). Thus far, no umbravirus is known to cause disease in sugarcane but the presence of similar viral sequences was recently reported in a sugarcane accession undergoing quarantine testing at the USDA in Beltsville, MD (Tahir et al. 2017). SCStV has been identified in germplasm collections in Guadeloupe and Reunion Island and most likely originated in Asia (Boukari et al. 2017). Several sequences that appear to belong to a species in the genus Chrysovirus were also obtained from sugarcane collected in Florida. Although chrysoviruses are mainly known to infect fungi, putative plant-infecting chrysoviruses have been reported recently (Li et al. 2013; Zhang et al. 2017). Further investigations are needed to determine whether the chrysovirus sequences identified in our study originated from a fungus that was infecting sugarcane or from a putative sugarcaneinfecting virus.

The incidence of viruses detected in this study varied widely. SCMV was found in only one sugarcane cultivar (CP72-2086) used as an inoculum source in the local breeding program at Canal Point, thus confirming that mosaic is well controlled with resistant cultivars in Florida (Rott et al. 2015). SCMMV and SCStV were found in only a few clones and Saccharum spp. of the germplasm collections and were absent in samples collected from commercial sugarcane fields. Therefore, these viruses do not currently affect local commercial sugarcane production. However, incidence of SCMMV may have been underestimated in this study because its full genomic sequence is not available yet, and several VANA reads may not have been properly identified in the BLAST searches.

SCBV was detected frequently ( $>50 \%$ ) in S. officinarum clones from the germplasm collections. This species is no longer cultivated but is a progenitor of modern sugarcane cultivars (Grivet et al. 2004). SCBV-specific sequences were also found in two samples from commercial sugarcane fields (cultivars CP73-1547 and CPCL99-4455). Because these cultivars were produced in Florida, it can be assumed that they were infected locally by SCBV. One of the insect vectors of this virus, the pink sugarcane mealybug ( $S$. sacchari), has been present on sugarcane within the Florida Everglades Agricultural Area for more than two decades (Hall et al. 2005). Because only two positive samples were found, the impact of SCBV on sugarcane production seems negligible at the present time. This may also suggest that modern sugarcane cultivars are resistant to the virus. However, ongoing monitoring for SCBV is warranted because biomass reductions due to SCBV have been reported for a former commercial cultivar in field trials in Florida (Comstock and Lockhart 1996).

Unlike the other three viruses, SCYLV sequences were found frequently $(73.5 \%)$ in both field and germplasm collection samples (Table 1). Similar results were obtained more than two decades ago: only 3 of 46 parental and commercial sugarcane hybrids in Florida tested negative for SCYLV in the late 1990s using serological and molecular detection assays (Comstock et al. 1998). Similarly, 75.8\% of the 157 clones of $S$. officinarum from the world collection of sugarcane and related grasses in Miami were found to be infected by SCYLV in 2001 (Comstock et al. 2001). These data suggested that SCYLV resistance is not a common feature in Florida sugarcane hybrids (CP varieties) or in the ancestral species $S$. officinarum. Among sugarcane-related species, $S$. spontaneum appeared to be the most resistant because 93 of the 100 clones from the Miami collection were found to be SCYLV negative (Comstock et al. 2001). However, we

Table 1. Occurrence of virus sequences in Saccharum and related species sampled in Florida in 2013 to 2014

\begin{tabular}{|c|c|c|c|c|c|c|}
\hline \multirow[b]{2}{*}{ Plant species ${ }^{b}$} & \multirow[b]{2}{*}{ Clones $^{\mathrm{c}}$} & \multicolumn{4}{|c|}{ Number of samples containing viral sequences $(\%)^{\mathrm{a}}$} & \multirow[b]{2}{*}{ Samples $^{\mathbf{d}}$} \\
\hline & & SCYLV & SCMV & SCMMV & SCBV & \\
\hline Erianthus spunknow & 2 & 0 & 0 & 1 & 1 & 2 \\
\hline Miscanthus floridulus & 1 & 0 & 0 & 0 & 0 & 1 \\
\hline Saccharum barberi & 1 & 0 & 0 & 1 & 1 & 1 \\
\hline S. edule & 1 & 0 & 0 & 1 & 0 & 1 \\
\hline S. officinarum & 73 & $59(79)$ & 0 & $10(13)$ & $42(56)$ & 75 \\
\hline S. robustum & 2 & 2 & 0 & 0 & 1 & 2 \\
\hline S. sinense & 1 & 1 & 0 & 0 & 0 & 1 \\
\hline S. spontaneum & 9 & 6 & 0 & 0 & 2 & 9 \\
\hline Saccharum spp. hybrid (FC) & 17 & $47(76)$ & 0 & 0 & $2(3)$ & 62 \\
\hline Saccharum spp. hybrid (GC) & 29 & $35(73)$ & 1 & 0 & $5(10)$ & 48 \\
\hline Sorghum plumosum & 1 & 0 & 0 & 0 & 0 & 1 \\
\hline Pennisetum sp. & 1 & 0 & 0 & 0 & 0 & 1 \\
\hline Total & 138 & $150(73.5)$ & $1(0.5)$ & $13(6.4)$ & $54(26.5)$ & 204 \\
\hline
\end{tabular}

a SCYLV = Sugarcane yellow leaf virus, SCMV = Sugarcane mosaic virus, SCMMV = Sugarcane mild mosaic virus, and SCBV = Sugarcane bacilliform virus .

$\mathrm{b}$ All botanical species of sugarcane and related species were sampled in the germplasm collections (GC) at Canal Point (plants maintained in pots near sugarcane breeding fields) and Clewiston (plants grown under commercial field conditions [FC]).

${ }^{\mathrm{c}}$ Total number of clones.

d Total number of samples. 
found SCYLV in six of nine $S$. spontaneum clones, suggesting that the virus might be more widespread in this species now than in 2001. Further testing for this virus is warranted.

Because limited resistance sources were available in commercial sugarcane and because mechanical screening for resistance to SCYLV is impossible, disease-free nurseries for commercial sales were started in Florida in 2000 (Rott et al. 2016). Planting material for these nurseries originated from pathogen-tested plants obtained by sugarcane tissue culture. This project was initiated to reduce the incidence of SCYLV and Leifsonia xyli subsp. xyli, the bacterium that causes sugarcane ratoon stunting. Based on data reported here, the project has had limited success in reducing SCYLV infection

A

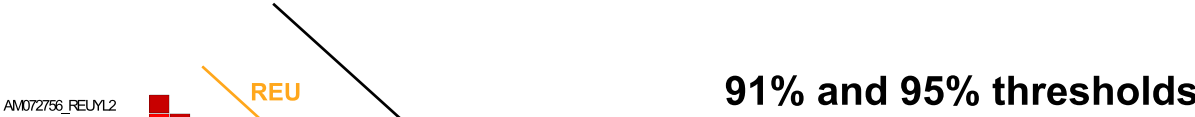

AMD72756 REUN2

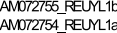
KYO52165_REUYL11 KY052166 REUYL15 KF477093_NCPCP502 KF-47092_GZGZ18 Gu570008_- Haw736110 Q5750007 t tanB77319 AMO72753 PERYL1b AM072752_PERYL1a
HO245320_CHGDZJ15 HO245317_CANGDWY1
HO245316_CANGDINR A249447-CP6535 AF157029_SCYLVA_V AY236971_SCYVVIND HO342888-aNNN1 AMD72750 BRAYL1 MH058008_FL86 GU190159_a-NFJ1
AM072751 CA-MY1 HC245321_a-NGDZ17 HO2 4532 _CANNNYY2
HO245319_CNGDZ14 HO245319_CANGDZ GU27735_chn1 MH058009_FL180 JF925155_INA4
JF925154 INDB FF925153_IND2 JF925153_ND2 KF680098_CBLK97154 HO245318_C-NGDW KT960995_Sarg1 1 KT1960906 Sorro? KT960997_Sarg3

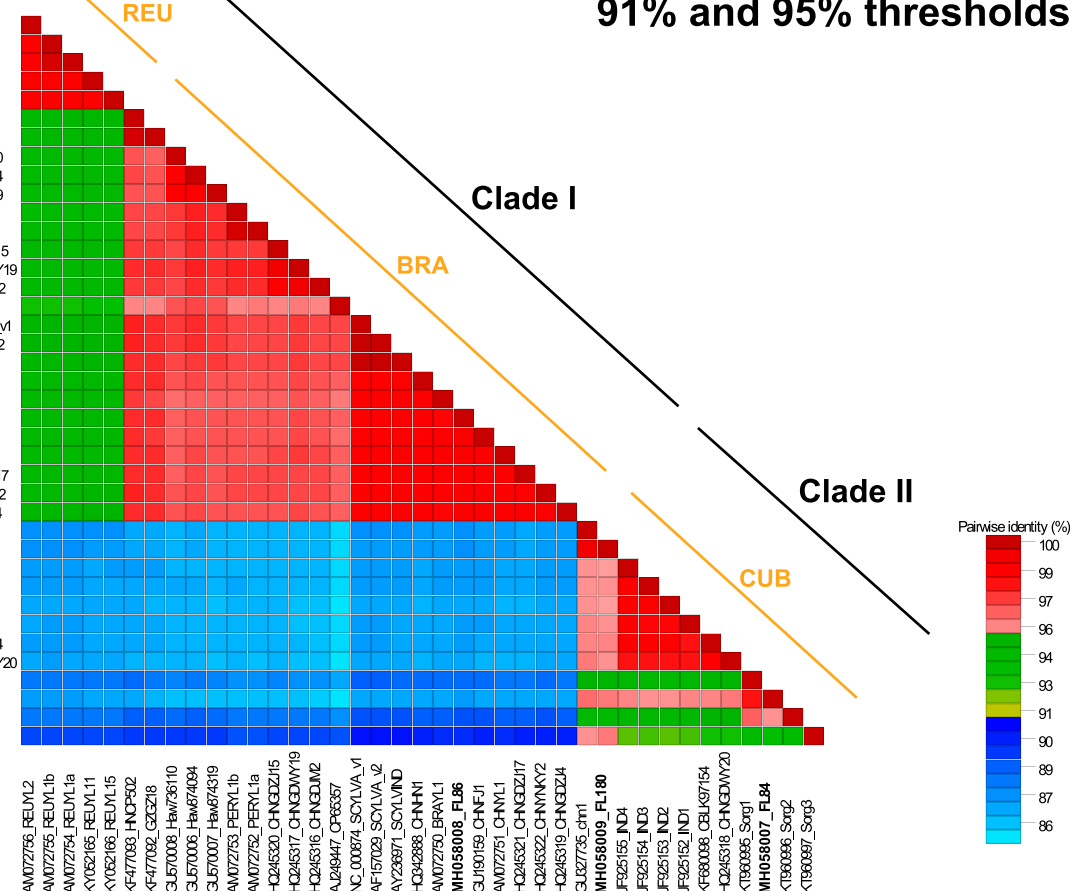

B

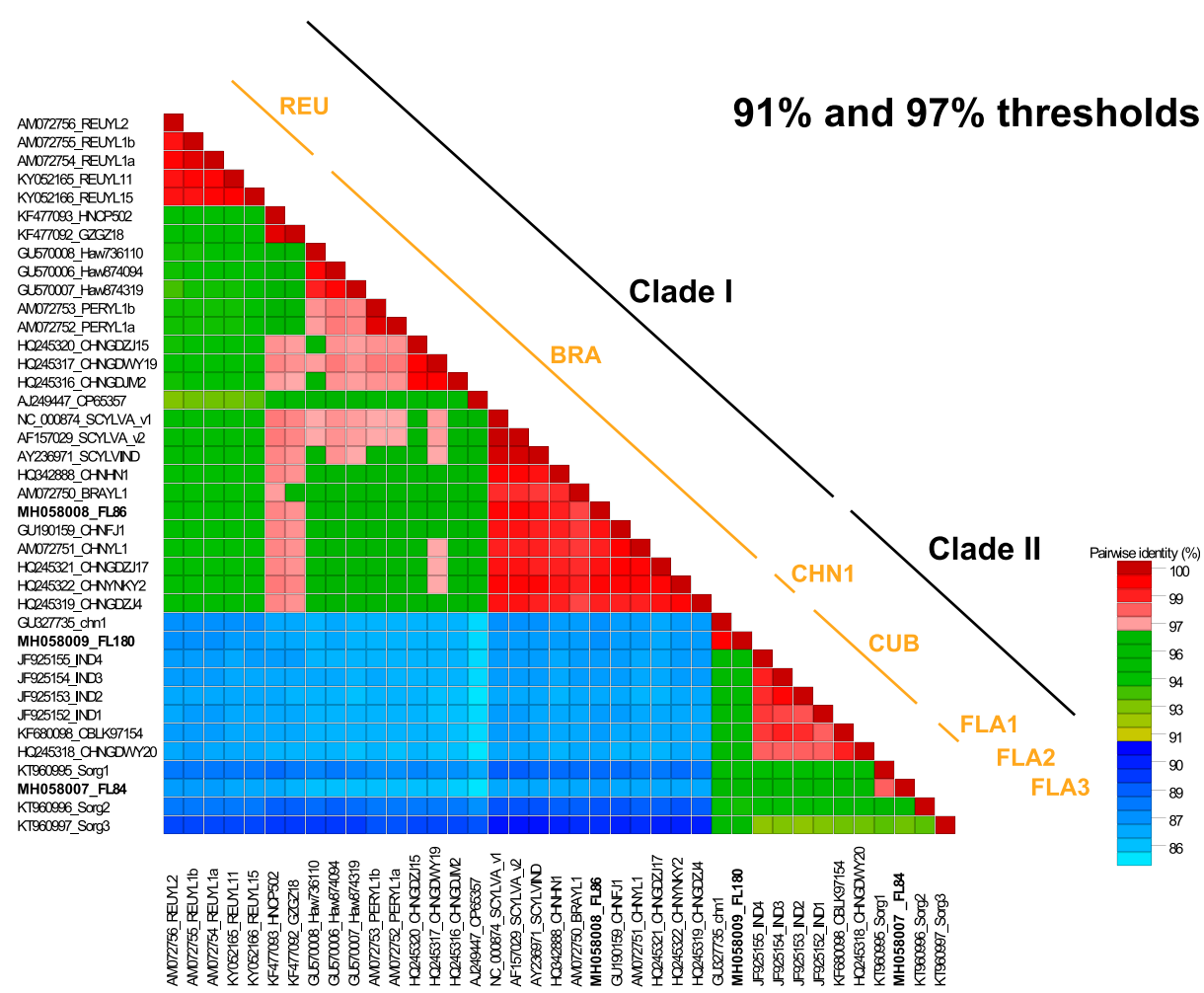

Fig. 2. Pairwise identity matrixes of 39 full-genome sequences of Sugarcane yellow leaf virus (SCYLV). A, Pairwise identity matrix with 91 and $95 \%$ thresholds. Distribution of SCYLV isolates in clades I and II (91\% threshold) is indicated by black bars. Distribution of SCYLV in genotypes REU, BRA, and CUB is indicated by orange bars (95\% threshold). B, Pairwise identity matrix with 91 and $97 \%$ thresholds. Distribution of SCYLV isolates in clades I and II (91\% threshold) is indicated by black bars. Distribution of SCYLV in genotypes REU, BRA, CHN1, CUB, FLA1, FLA2, and FLA3 is indicated by orange bars (97\% threshold). 
levels in Florida commercial fields. Rapid reinfection of healthy material probably occurs under field conditions, most likely because of high populations of the aphid vector (M. sacchari) during some periods of sugarcane cultivation (Hall 1987). Given the prevalence of SCYLV and its effect on yields (Comstock and Miller 2004), one can conclude that yellow leaf is currently responsible for sugarcane yield losses in Florida.

Prior to this study, only SCYLV isolates from phylogenetic clade I (genotype BRA) were known to occur in Florida sugarcane (Abu Ahmad et al. 2006b). Furthermore, the two complete genome sequences available in GenBank from Florida isolates (AF157029.1 for isolate SCYLV-A and AJ249447.1 for isolate SCYLV-F) belong to this clade (Moonan et al. 2000; Smith et al. 2000). In our study, more than $40 \%$ of the samples with SCYLV $c p$ sequences belonged to phylogenetic clade II. Isolates of both clades were found in samples collected from the germplasm collections and the commercial fields. However, more clade II isolates were detected in S. officinarum than in commercial sugarcane hybrids. Isolates of clade I appeared more prevalent than isolates of clade II in sugarcane hybrids regardless of their sampling location (germplasm collections or commercial fields). This suggests that isolates of clade II were only recently introduced to Florida or that they more effectively infect botanical species of sugarcane rather than modern cultivars. Future snapshots of the distribution of SCYLV isolates in Florida may reveal changes in the population structure of SCYLV.

Currently, eight genotypes are recognized for SCYLV (BRA, CHN1, CHN3, CUB, HAW, IND, PER, and REU), based mainly on the position of virus isolates in phylogenetic trees reconstructed with full coding sequences (Abu Ahmad et al. 2006a; Chinnaraja et al. 2013; Lin et al. 2014; Wang et al. 2012). However, this grouping approach is lacking a standardized and rigorous method based on sequence alignment and pairwise identity calculation protocols. These latter protocols have recently been widely used with other viruses to define species, strain, or variant demarcation thresholds (Varsani and Krupovic 2017; Varsani et al. 2014, 2017). In our study, sequence alignment and pairwise identity calculation protocols based on 39 full genome sequences of SCYLY allowed us to identify possible sequence demarcation thresholds at 90 to 91,95 , and $97 \%$ identity.

Although a $91 \%$ threshold could be used for SCYLV clade (or strain) demarcation, it remains difficult to choose between 95 or 97\% for the genotype (or variant) demarcation. The use of a 95\% threshold would split clade I into two genotypes, REU and BRA, which were among the first four genotypes described for SCYLV (Abu Ahmad et al. 2006a). Genotype BRA would be a large genotype including isolates previously attributed to genotypes HAW, PER, and CHN3. Clade II would contain a single genotype called CUB because it was the first genotype reported for this clade (Abu Ahmad et al. 2006a).

A $97 \%$ sequence demarcation threshold would fit best with the current description of SCYLV genotypes, including REU and

Table 2. Distribution of clade I and II isolates of Sugarcane yellow leaf virus (SCYLV) in Saccharum officinarum and Saccharum hybrids sampled in Florida in 2013 to 2014

\begin{tabular}{lccccc}
\hline & & \multicolumn{3}{c}{$\begin{array}{c}\text { Number of samples } \\
\text { containing viral sequences } \\
\text { of SCYLV clade }\end{array}$} \\
\cline { 3 - 6 } $\begin{array}{l}\text { Plant species } \\
\text { (sampling location) }\end{array}$ & Total samples & I & II & I and II \\
\hline $\begin{array}{c}\text { S. officinarum (germplasm } \\
\text { collections) }\end{array}$ & 28 & 3 & 21 & 4 \\
$\begin{array}{c}\text { Saccharum spp. hybrid } \\
\text { (commercial fields) }\end{array}$ & 23 & 16 & 7 & 0 \\
$\begin{array}{c}\text { Saccharum spp. hybrid } \\
\text { (germplasm collections) }\end{array}$ & 20 & 18 & 2 & 0 \\
Total & 71 & $37(52 \%)$ & $30(42 \%)$ & $4(6 \%)$ \\
\hline
\end{tabular}

${ }^{\text {a Clade sequences were identified based on } 12 \text { single-nucleotide }}$ polymorphisms
BRA for clade I. Clade II would comprise genotypes CHN1, CUB (including genotype IND isolates), and three novel genotypes from Florida (FLA1, FLA2, and FLA3). Using this 97\% threshold, Florida isolates FL86 and FL180 reported in this study clustered with genotypes BRA and CHN1, respectively. In contrast, isolate FL84 belonged to genotype FLA1, along with isolate Sorg1 that was recently obtained from sweet sorghum in Florida (ElSayed et al. 2018). Two additional isolates of SCYLV from sweet sorghum in Florida (Sorg2 and Sorg3) (ElSayed et al. 2018), which formed two separate lineages (Fig. 1), would be attributed to new genotypes FLA2 and FLA3, respectively. The biological significance of these genetic differences remains to be determined.

The metagenomic-based screening and the RT-PCR assay for detection of SCYLV gave concordant results for 164 (80.4\%) of the 204 samples. The remaining 40 samples were all ones that tested positive but only by metagenomics or by RT-PCR, not by both. This supports the recommendation that at least two methods should be used when highly accurate detection of SCYLV is critical, such as in a sugarcane quarantine environment (Guinet-Brial et al. 2013; Thompson 2018). The concerns about relying on metagenomics as the sole detection technique stem from the extraordinary importance of having good library preparations and meticulously avoiding cross-contamination. On the other hand, metagenomic-based screening might be more sensitive than RT-PCR, thus resulting in detection of very low virus titers in some samples that tested negative by RT-PCR (Al Rwahnih et al. 2015). Further comparative study is needed to confirm this.

Plant viral metagenomics has become a powerful tool for investigating virus etiology enigmas, assessing diversity of viruses, and identifying known and potentially new viruses (Bernardo et al. 2013, 2018; Roossinck 2012; Roossinck et al. 2015; Roumagnac et al. 2018). In addition to known sugarcane viruses, we identified two new sugarcane-infecting viruses in Florida: SCStV (Boukari et al. 2017) and an umbravirus. Future work will include full genome sequencing and characterization of the umbravirus, and developing diagnostic methods for both new viruses. Regular screening of the sugarcane virome by metagenomics will also allow us to monitor the spread of viral diseases of sugarcane in Florida, and assess the efficiency of disease control using resistant cultivars.

\section{Acknowledgments}

We thank B. Sakr, R. Perdomo, and D. Luzuriaga (Florida Crystals), E. Esparza, L. Davis, and M. Irey (United States Sugar Corporation), K. Polacik and J. Shine (Sugar Cane Growers Cooperative of Florida), and J. Todd (USDA-ARS) for their help in collecting the plant samples; A. M. Jameson for sample preparation; and G. Kinard for critical review of the manuscript.

\section{Literature Cited}

Abu Ahmad, Y., Rassaby, L., Royer, M., Borg, Z., Braithwaite, K. S., Mirkov, T. E., Irey, M. S., Perrier, X., Smith, G. R., and Rott, P. 2006a. Yellow leaf of sugarcane is caused by at least three different genotypes of sugarcane yellow leaf virus, one of which predominates on the Island of Réunion. Arch. Virol. 151:1355-1371.

Abu Ahmad, Y., Royer, M., Daugrois, J.-H., Costet, L., Lett, J.-M., Victoria, J. I., Girard, J.-C., and Rott, P. 2006b. Geographical distribution of four Sugarcane yellow leaf virus genotypes. Plant Dis. 90:1156-1160.

Al Rwahnih, M., Daubert, S., Golino, D., Islas, C., and Rowhani, A. 2015. Comparison of next-generation sequencing versus biological indexing for the optimal detection of viral pathogens in grapevine. Phytopathology 105:758-763.

Altschul, S. F., Gish, W., Miller, W., Myers, E. W., and Lipman, D. J. 1990. Basic local alignment search tool. J. Mol. Biol. 215:403-410.

Bernardo, P., Albina, E., Eloit, M., and Roumagnac, P. 2013. Métagénomique virale et pathologie [Pathology and viral metagenomics, a recent history] Med. Sci. (Paris) 29:501-508.

Bernardo, P., Charles-Dominique, T., Barakat, M., Ortet, P., Fernandez, E., Filloux, D., Hartnady, P., Rebelo, T. A., Cousins, S. R., Mesleard, F., Cohez, D., Yavercovski, N., Varsani, A., Harkins, G. W., Peterschmitt, M., Malmstrom, C. M., Martin, D. P., and Roumagnac, P. 2018. Geometagenomics illuminates the impact of agriculture on the distribution and prevalence of plant viruses at the ecosystem scale. ISME J. 12: 173-184.

Boukari, W., Alcalá-Briseño, R. I., Kraberger, S., Fernandez, E., Filloux, D., Daugrois, J. H., Comstock, J. C., Lett, J. M., Martin, D., Varsani, A., Roumagnac, P., Polston, J. E., and Rott, P. C. 2017. Occurrence of a novel mastrevirus in sugarcane germplasm collections in Florida, Guadeloupe and Réunion. BMC Virol. J. 14:146. Candresse, T., Filloux, D., Muhire, B., Julian, C., Galzi, S., Fort, G., Bernardo, P., Daugrois, J. H., Fernandez, E., Martin, D. P., Varsani, A., and Roumagnac, P. 
2014. Appearances can be deceptive: Revealing a hidden viral infection with deep sequencing in a plant quarantine context. PLoS One 9:e102945.

Chinnaraja, C., Viswanathan, R., Karuppaiah, R., Bagyalakshmi, K., Malathi, P., and Parameswari, B. 2013. Complete genome characterization of Sugarcane yellow leaf virus from India: Evidence for RNA recombination. Eur. J. Plant Pathol. 135:335-349.

Comstock, J. C., Irey, M. S., Lockhart, B. E. L., and Wang, Z. K. 1998. Incidence of yellow leaf syndrome in CP cultivars based on polymerase chain reaction and serological techniques. Sugar Cane 4:21-24.

Comstock, J. C., Irvine, J. E., and Miller, J. D. 1994. Yellow leaf syndrome appears on the United States mainland. Sugar J. 56:33-35.

Comstock, J. C., and Lockhart, B. E. L. 1990. Widespread occurrence of sugarcane bacilliform virus in U.S. sugarcane germplasm collections. Plant Dis. 74:530.

Comstock, J. C., and Lockhart, B. E. L. 1996. Effect of sugarcane bacilliform virus on biomass production of three sugarcane cultivars. Sugar Cane 4:12-15.

Comstock, J. C., and Miller, J. D. 2004. Yield comparisons: Disease-free tissueculture versus bud-propagated sugarcane plants and healthy versus yellow leaf infected plants. J. Am. Soc. Sugar Cane Technol. 24:31-40.

Comstock, J. C., Miller, J. D., and Schnell, R. J. 2001. Incidence of sugarcane yellow leaf virus in clones maintained in the world collection of sugarcane and related grasses at the United States National Repository in Miami, Florida. Sugar Tech 3:128-133.

Darriba, D., Taboada, G. L., Doallo, R., and Posada, D. 2012. jModelTest 2: More models, new heuristics and parallel computing. Nat. Methods 9:772.

Edgar, R. C. 2004. MUSCLE: a multiple sequence alignment method with reduced time and space complexity. BMC Bioinf. 5:113.

ElSayed, A. I., Boulila, M., Odero, D. C., and Komor, E. 2018. Phylogenetic and recombination analysis of sorghum isolates of Sugarcane yellow leaf virus. Plant Pathol. 67:221-232.

Girard, J. C., Fernandez, E., Daugrois, J. H., Roques, D., Roumagnac, P., and Rott, P. 2010. Genetic diversity of Sugarcane yellow leaf virus in a sugarcane selection plot in Guadeloupe (FWI). Proc. Int. Soc. Sugar Cane Technol. 27: 1123-1129.

Grisham, M. P. 2000. Mosaic. Pages 249-254 in: A Guide to Sugarcane Diseases. P. Rott, R. A. Bailey, J. C. Comstock, B. J. Croft, and A. S. Saumtally, eds. La Librairie du Cirad, Montpellier, France.

Grivet, L., Daniels, C., Glazmann, J. C., and D'Hont, A. 2004. A review of recent molecular genetics evidence for sugarcane evolution and domestication. Ethnobot. Res. Appl. 2:009-017.

Guindon, S., Dufayard, J. F., Lefort, V., Anisimova, M., Hordijk, W., and Gascuel, O. 2010. New algorithms and methods to estimate maximum-likelihood phylogenies: Assessing the performance of PhyML 3.0. Syst. Biol. 59:307-321.

Guinet-Brial, I., Girard, J. C., Roumagnac, P., Daugrois, J. H., Fernandez, E., and Rott, P. 2013. Visacane, an innovative quarantine tool for the exchange of pest and disease-free sugarcane germplasm. Proc. Int. Soc. Sugar Cane Technol. 28: 890-896.

Hall, D. G. 1987. The sugarcane aphid, Melanaphis sacchari (Zehntner), in Florida. J. Am. Soc. Sugar Cane Technol. 7:26-29.

Hall, D. G., Konstantinov, A. S., Hodges, G. S., Sosa, O., Welbourn, C., and Westcott, R. L. 2005. Insects and mites new to Florida sugarcane. J. Am. Soc. Sugar Cane Technol. 25:143-156.

Huang, X. Q., and Madan, A. 1999. CAP3: A DNA sequence assembly program. Genome Res. 9:868-877.

Koike, H., and Gillaspie, A. G., Jr. 1989. Mosaic. Pages 301-322 in: Diseases of Sugarcane. Major Diseases. C. Ricaud, B. T. Egan, A. G. Gillaspie, Jr., and C. G. Hughes, eds. Elsevier Science Publishers B.V., Amsterdam.

Li, L., Liu, J., Xu, A., Wang, T., Chen, J., and Zhu, X. 2013. Molecular characterization of a trisegmented chrysovirus isolated from the radish Raphanus sativus. Virus Res. 176:169-178.

Lin, Y.-H., Gao, S.-J., Damaj, M. B., Fu, H.-Y., Chen, R.-K., and Mirkov, T. E. 2014. Genome characterization of Sugarcane yellow leaf virus from China reveals a novel recombinant genotype. Arch. Virol. 159:1421-1429.

Lockhart, B. E. L., and Autrey, L. J. C. 1988. Occurrence in sugarcane of a bacilliform virus related serologically to banana streak virus. Plant Dis. 72: 230-233.

Lockhart, B. E. L., and Autrey, L. J. C. 2000a. Mild mosaic. Pages 245-248 in: A Guide to Sugarcane Diseases. P. Rott, R. A. Bailey, J. C. Comstock, B. J. Croft, and A. S. Saumtally, eds. La Librairie du Cirad, Montpellier, France.

Lockhart, B. E. L., and Autrey, L. J. C. 2000b. Sugarcane bacilliform virus. Pages 268-272 in: A Guide to Sugarcane Diseases. P. Rott, R. A. Bailey, J. C. Comstock, B. J. Croft, and A. S. Saumtally, eds. La Librairie du Cirad, Montpellier, France.
Lockhart, B. E. L., Autrey, L. J. C., and Comstock, J. C. 1992. Purification and serology of sugarcane mild mosaic virus, a mealybug-transmitted closterolike virus. Phytopathology 82:691-695.

Moonan, F., Molina, J., and Mirkov, T. E. 2000. Sugarcane yellow leaf virus: An emerging virus that has evolved by recombination between luteoviral and poleroviral ancestors. Virology 269:156-171.

Muhire, B. M., Varsani, A., and Martin, D. P. 2014. SDT: A virus classification tool based on pairwise sequence alignment and identity calculation. PLoS One 9:e108277.

Muthukumar, V., Melcher, U., Pierce, M., Wiley, G. B., Roe, B. A., Palmer, M. W., Thapa, V., Akhtar, A., and Tao, D. 2009. Non-cultivated plants of the Tallgrass Prairie Preserve of northeastern Oklahoma frequently contain viruslike sequences in particulate fractions. Virus Res. 141:169-173.

Muthukumar, V., Wiley, G. B., Pierce, M. L., Roe, B. A., and Melcher, U. 2007. Metagenomics for identification of novel plant viruses. Phytopathology 97: S81-S82.

Palanga, E., Filloux, D., Martin, D. P., Fernandez, E., Gargani, D., Ferdinand, R. Zabre, J., Bouda, Z., Neya, J. B., Sawadogo, M., Traore, O., Peterschmitt, M., and Roumagnac, P. 2016. Metagenomic-based screening and molecular characterization of cowpea-infecting viruses in Burkina Faso. PLoS One 11: e0165188.

Roossinck, M. J. 2012. Plant virus metagenomics: Biodiversity and ecology. Annu. Rev. Genet. 46:359-369.

Roossinck, M. J., Martin, D. P., and Roumagnac, P. 2015. Plant virus metagenomics: Advances in virus discovery. Phytopathology 105:716-727.

Roossinck, M. J., Saha, P., Wiley, G., Quan, J., White, J. D., Lai, H., Chavarría, F., Shen, G., and Roe, B. 2010. Ecogenomics: Using massively parallel pyrosequencing to understand virus ecology. Mol. Ecol. 19:81-88.

Rott, P., Bailey, R. A., Comstock, J. C., Croft, B. J., and Saumtally, A. S., eds. 2000 A Guide to Sugarcane Diseases. La Librairie du Cirad, Montpellier, France.

Rott, P., Comstock, J. C., Gilbert, R. A., and Sandhu, H. S. 2015. Sugarcane mosaic. IFAS Extension SS-AGR-209. University of Florida, Gainesville.

Rott, P., Mirkov, T. E., Schenck, S., and Girard, J. C. 2008. Recent advances in research on Sugarcane yellow leaf virus, the causal agent of sugarcane yellow leaf. Sugar Cane Int. 26:18-27.

Rott, P. C., Kaye, C., Naranjo, M., Shine, J. M., Jr., Sood, S., Comstock, J. C., and Raid, R. N. 2016. Controlling sugarcane diseases in Florida: A challenge in constant evolution. Proc. Int. Soc. Sugar Cane Technol. 29:595-600.

Roumagnac, P., Mollov, D., Daugrois, J.-H., and Filloux, D. 2018. Viral metagenomics and sugarcane pathogens. Pages 183-200 in: Achieving Sustainable Cultivation of Sugarcane. P. Rott, ed. Burleigh Dodds Science Publishing, Cambridge.

Smith, G. R., Borg, Z., Lockhart, B. E. L., Braithwaite, K. S., and Gibbs, M. 2000 Sugarcane yellow leaf virus: A novel member of the Luteoviridae that probably arose by inter-species recombination. J. Gen. Virol. 81:1865-1869.

Tahir, M. N., Grinstead, S., and Mollov, D. S. 2017. New virus from the family Tombusviridae infecting sugarcane. (Abstr.) Phytopathology 107:S5.98.

Thompson, N. 2018. Ensuring biosecurity in sugarcane cultivation. Pages 157-182 in: Achieving Sustainable Cultivation of Sugarcane. P. Rott, ed. Burleigh Dodds Science Publishing, Cambridge.

Todd, J., Wang, J., Glaz, B., Sood, S., Ayala-Silva, T., Nayak, S. N., Glynn, N. C., Gutierrez, O. A., Kuhn, D. N., Tahir, M., and Comstock, J. C. 2014. Phenotypic characterization of the Miami world collection of sugarcane (Saccharum spp.) and related grasses for selecting a representative core. Genet. Resour. Crop Evol. 61:1581-1596.

Varsani, A., and Krupovic, M. 2017. Sequence-based taxonomic framework for the classification of uncultured single-stranded DNA viruses of the family Genomoviridae. Virus Evol. 3:vew037.

Varsani, A., Navas-Castillo, J., Moriones, E., Hernandez-Zepeda, C., Idris, A., Brown, J. K., Murilo Zerbini, F., and Martin, D. P. 2014. Establishment of three new genera in the family Geminiviridae: Becurtovirus, Eragrovirus and Turncurtovirus. Arch. Virol. 159:2193-2203.

Varsani, A., Roumagnac, P., Fuchs, M., Navas-Castillo, J., Moriones, E., Idris, A. Briddon, R. W., Rivera-Bustamante, R., Murilo Zerbini, F., and Martin, D. P. 2017. Capulavirus and Grablovirus: Two new genera in the family Geminiviridae. Arch. Virol. 162:1819-1831.

Wang, M.-Q., Xu, D. L., Li, R., and Zhou, G. H. 2012. Genotype identification and genetic diversity of Sugarcane yellow leaf virus in China. Plant Pathol. 61: 986-993.

Zhang, J., Zhao, Z., Hu, R., Guo, L., Zheng, L., Du, Z., Wu, Z., Fang, S., Zhang, S., and Liu, Y. 2017. The genome sequence of Brassica campestris chrysovirus 1, a novel putative plant-infecting tripartite chrysovirus. Arch. Virol. 162:1107-1111. 